\title{
A new risk scoring model for prediction of poor coronary collateral circulation in acute non-ST-elevation myocardial infarction
}

\author{
Mehmet İleri ${ }^{1}$, Ümit Güray ${ }^{1}$, Ertan Yetkin ${ }^{2}$, Havva Tuğba Gürsoy ${ }^{1}$, \\ Pınar Türker Bayır ${ }^{1}$, Deniz Şahin ${ }^{1}$, Özgül Uçar Elalmış ${ }^{1}$, Yahya Büyükaşık ${ }^{3}$ \\ ${ }^{1}$ Department of Cardiology, Ankara Numune Education and Research Hospital, Ankara, Turkey \\ ${ }^{2}$ Department of Cardiology, Ortadoğu Hospital, Mersin, Turkey \\ ${ }^{3}$ Department of Hematology, Faculty of Medicine, Hacettepe University, Ankara, Turkey
}

\begin{abstract}
Background: We aimed to investigate the clinical features associated with development of coronary collateral circulation (CCC) in patients with acute non-ST-elevation myocardial infarction (NSTEMI) and to develop a scoring model for predicting poor collateralization at hospital admission.

Methods: The study enrolled 224 consecutive patients with NSTEMI admitted to our coronary care unit. Patients were divided into poor (grade 0 and 1) and good (grade 2 and 3) CCC groups. Results: In logistic regression analysis, presence of diabetes mellitus, total white blood cell (WBC) and neutrophil counts and neutrophil to lymphocyte ratio (NLR) were found as independent positive predictors of poor CCC, whereas older age ( $\geq 70$ years) emerged as a negative indicator. The final scoring model was based on 5 variables which were significant at $p<0.05$ level following multivariate analysis. Presence of diabetes mellitus, and elevated total WBC $\left(\geq 7.85 \times 10^{3} / \mu L\right)$ and neutrophil counts $\left(\geq 6.25 \times 10^{3} / \mu L\right)$ were assigned with 2 points; high $N L R$ ( $\geq 4.5$ ) with 1 point and older age ( $\geq 70$ years old) with -1 point. Among 30 patients with risk score $\leq 1,29$ had good CCC (with a 97\% negative predictive value). On the other hand, 139 patients had risk score $\geq 4$; out of whom, 130 (with a 93.5\% positive predictive value) had poor collateralization. Sensitivity and specificity of the model in predicting poor collateralization in patients with scores $\leq 1$ and $\geq 4$ were $99.2 \%$ (130/131) and +76.3 (29/38), respectively.
\end{abstract}

Conclusions: This study represents the first prediction model for degree of coronary collateralization in patients with acute NSTEMI. (Cardiol J 2016; 23, 1: 107-113)

Key words: coronary collateral circulation, non-ST-elevation myocardial infarction, risk scoring

\section{Introduction}

The apparent prognostic implications of coronary collateral circulation (CCC) makes it necessary to have a better understanding of the factors promoting collateral development. In this study, we aimed to investigate the clinical features associated with development of CCC in patients with acute non-ST-elevation myocardial infarction (NSTEMI) and to develop a scoring model for predicting poor collateralization at hospital admission.

Address for correspondence: Mehmet Ileri, MD, Department of Cardiology, Ankara Numune Education and Research Hospital, Samur Sokak, 30/10, Kurtuluş, Ankara, Turkey, tel: ++90 505 485 9803, e-mail: maraspoli2020@gmail.com 


\section{Methods}

We prospectively enrolled 224 consecutive patients with NSTEMI admitted to our coronary care unit within $24 \mathrm{~h}$ of symptom onset and scheduled to undergo coronary angiography within $48 \mathrm{~h}$ of hospitalization. Patients who did not have a significant stenosis ( $\geq 70 \%$ ) in at least one of the major epicardial coronary arteries in coronary angiograms were excluded from the study. Left main coronary artery narrowing of $\geq 50 \%$ was also considered significant. NSTEMI was diagnosed in the presence of two following criteria: (1) an accelerating pattern of prolonged (lasting $>20 \mathrm{~min}$ ) angina or recurrent episodes of angina either at rest or during minimal exertion within the $48 \mathrm{~h}$; and (2) levels of cardiac biomarkers (troponin or creatine kinase MB isoenzymes) above the upper limit of the normal range. The exclusion criteria were overt congestive heart failure, idiopathic dilated or hypertrophic cardiomyopathy, chronic active pulmonary disease, history of renal or hepatic dysfunction, inflammatory rheumatic disease, recent infection, cancer, and pregnancy.

According to our early invasive strategy, quantitative coronary angiography was performed in all patients within $48 \mathrm{~h}$ after admission in multiple orthogonal projections using the Judkins technique by 2 experienced independent interventional cardiologists. Decisions regarding the revascularization method were left to the discretion of the interventionalists. When percutaneous coronary intervention was believed appropriate on the basis of coronary anatomy, culprit vessel stenting was performed in the same setting. In the case of multivessel interventions, non-culprit vessels could be revascularized in the same setting or in a staged procedure. Coronary collateral grading was carried out by 2 experienced cardiologists who are not informed of the clinical characteristics and biochemical results of the study patients. Collateral development was graded according to the Cohen-Rentrop method [1]: grade 0 (no filling of any collateral vessels); grade 1 (filling of side branches of the artery to be perfused by collateral vessels without visualization of the epicardial segment); grade 2 (partial filling of the epicardial segment by collateral vessels); grade 3 (complete filling of the epicardial artery by collateral vessels). Patients were then divided into two groups according to their collateral grades; with the first group having poorly developed CCC (grade 0 and 1 ) and the second group having well-developed CCC (grade 2 and 3).
Blood samples at hospital admission were drawn in the emergency room from the antecubital vein by careful venipuncture using a 21 -gauge needle attached to a sterile syringe without stasis. Hematological parameters such as red blood cells, platelets, white blood cells (WBC) and their subtypes were measured in blood collected in dipotassium ethylenediaminetetraacetic acid (EDTA) containing tubes by flow cytometry in an automated blood cell counter (Sysmex, XT-2000i) immediately within 30 min after sampling. Neutrophil to lymphocyte ratio (NLR) was calculated as the mean value of the ratio of neutrophils to lymphocytes, both obtained from the same blood sample.

The study was approved by the local bioethical committee and all patients gave their informed consent.

\section{Statistical analysis}

Statistical Package for Social Sciences (SPSS) version 17.0 (SPSS Inc., Chicago, Illinois, USA) was used for all statistical calculations. A 2-tailed $\mathrm{p}$ value lower than 0.05 was considered to be statistically significant. The categorical variables were shown as numbers of cases with percentages. Continuous variables were defined as mean \pm standard deviation for parametric; and median with minimum and maximum levels for nonparametric variables. Student's $t$-test was used for analysis of continuous variables that were normally distributed. The $\chi^{2}$ test (or Fisher's Exact test if required by sample size) was used to compare categorical data. The possible factors identified with univariate testing were further entered into multiple logistic regression analysis to determine the independent predictors of poor collateralization. A scoring system for prediction of poor collateralization was developed depending on the results of logistic regression analysis as just previously described [2]. Briefly, the lowest regression coefficient (B value) of significant parameters in multivariate analysis was scored with 1 point. Regression coefficients of other significant parameters were divided by the lowest one and the results were rounded to the nearest integer. Consequently, every significant parameter in logistic regression analysis was scored with a point correlated with its impact. These individual points were then added together to provide a total risk score for every patient. Receiver operating characteristic (ROC) curve analysis was performed as needed in order to determine the best cut-off values for numerical values including the developed score in prediction of poor collateralization. 


\section{Results}

\section{Univariate analysis}

Baseline clinical characteristics and laboratory findings including hematological parameters in study population at hospital admission were summarized in Table 1. Data also included the comparison of these parameters in poor and good CCC groups. A total of 224 patients (146 male and 78 female, mean age $65 \pm 9$ years old) were enrolled in this study. Rentrop coronary grade was distributed as followed among patients: $92(41.1 \%)$ with grade $0,53(23.7 \%)$ with grade $1,47(21.0 \%)$ with grade 2 and $32(14.3 \%)$ with grade 3 . There were 145 patients in poor CCC group and 79 patients in good CCC group. Both groups were similar in terms of the presence of hyperlipidemia, body mass index, left ventricular ejection fraction, previous medications and biochemical measurements (serum creatinine, uric acid, gamma-glutamyl transferase, troponin). Poor CCC group included fewer patients $\geq 70$ years old and more female gender compared to good CCC group (19.3\% vs. $43.0 \%, \mathrm{p}<0.001$ and $40.7 \%$ vs. $24.01 \%, \mathrm{p}=0.028$, respectively). Diabetes mellitus, hypertension and cigarette smoking were more common in poor collateralization group compared with good collateralization (71 vs. $21, \mathrm{p}<0.001 ; 87$ vs. $24, \mathrm{p}<0.001$ and 94 vs. $40, p=0.038$, respectively). Among the hematological parameters; red blood cell, platelet, lymphocyte and monocyte counts and platelet to lymphocyte ratio did not differ between the two groups. However, WBC count, neutrophil count and NLR were significantly higher in the poor CCC group compared to the good CCC group (9.01 \pm \pm 0.95 vs. $7.57 \pm 0.35, \mathrm{p}<0.001 ; 7.29 \pm 0.81$ vs. $6.00 \pm 0.33, \mathrm{p}<0.001$ and $5.37 \pm 1.03$ vs. $4.31 \pm$ $\pm 0.63, \mathrm{p}<0.001$, respectively). Angiographic and procedural characteristics in two groups were shown in Table 1. Patients with poor CCC had lower degree of stenosis (\% of luminal diameter) in the culprit vessel $(78.1 \pm 8.3$ vs. $83.6 \pm 9.8, \mathrm{p}<0.001)$ compared to those with good CCC.

\section{Multivariate analysis}

The possible factors identified in univariate testing (age, gender, diabetes mellitus, hypertension, smoking, WBC count, neutrophil count and NLR) were further entered into logistic regression analysis to determine the independent predictors of poor CCC (Table 2). In multivariate analysis, presence of diabetes mellitus, WBC count, neutrophil count and NLR were found as independent positive predictors of poor CCC whereas older age
( $\geq 70$ years) emerged as a negative indicator. The final model was based on 5 variables which were significant at the $p<0.05$ level following multivariable logistic regression analysis. The score includes these variables namely; age, diabetes mellitus, WBC count, neutrophil count and NLR. Optimal cut-off values for WBC count, neutrophil count, and NLR as determined by ROC analysis were $7.85 \times$ $\times 10^{3} / \mu \mathrm{L}, 6.25 \times 10^{3} / \mu \mathrm{L}$ and 4.5 , respectively. These three parameters were still significantly associated with $\mathrm{CCC}$ when they were categorized by their cut-off levels.

\section{Model for prediction of poor CCC}

As shown in Table 3, presence of diabetes mellitus, and high levels of WBC $\left(\geq 7.85 \times 10^{3} / \mu \mathrm{L}\right)$ and neutrophil counts $\left(\geq 6.25 \times 10^{3} / \mu \mathrm{L}\right)$ were assigned with 2 points; high NLR $(\geq 4.5)$ with 1 point and older age ( $\geq 70$ years old) with -1 point. Consequently the score ranged between -1 to 7 points. Table 4 summarizes the comparison of risk scores in patients with poor and good CCC. Among 30 patients with risk score $\leq 1,29$ had good CCC (with a $97 \%$ negative predictive value). On the other hand, 139 patients had risk score $\geq 4$; out of whom, 130 (with a $93.5 \%$ positive predictive value) had poor collateralization. Consequently, the model was informative in 169 patients out of 224 $(75.4 \%)$ with their scores either $\leq 1(\mathrm{n}=30)$ or $\geq 4(\mathrm{n}=139)$. Sensitivity and specificity of the model in predicting poor collateralization in patients with scores $\leq 1$ and $\geq 4$ were $99.2 \%(130 / 131)$ and +76.3 (29/38), respectively.

\section{Discussion}

Coronary collateral flow can provide an alternative blood supply to myocardium jeopardized by stenosis or occlusion of a coronary artery. A recent meta-analysis of 12 studies enrolling 6,529 patients evaluated the effect of collateral function on all cause mortality in a mixed population of coronary artery disease (CAD) [3]. Results showed that patients with well developed collaterals had reduced mortality compared to those with poor collaterals. These data suggest that assessment of collateral function might be useful for risk stratification in patients with CAD. Our study group includes patients with acute NSTEMI. In the presence of persistent coronary occlusion, coronary collateral flow in the infracted area tends to increase in the days and weeks following the acute event. However, some investigators have shown that even in the first $6 \mathrm{~h}$ following acute coronary occlusion, collateral 
Table 1. Baseline clinical and laboratory findings in study population; comparison between poor and good coronary collateral circulation (CCC) groups.

\begin{tabular}{|c|c|c|c|c|}
\hline & All $(n=224)$ & Poor CCC $(n=145)$ & Good CCC (n = 79) & $\mathbf{P}$ \\
\hline \multicolumn{5}{|l|}{ Clinical and laboratory findings } \\
\hline Age $\geq 70$ years & $62(27.7 \%)$ & $28(19.3 \%)$ & $34(43.0 \%)$ & $<0.001$ \\
\hline Female & $78(34.8 \%)$ & $59(40.7 \%)$ & $19(24.01 \%)$ & 0.028 \\
\hline Body mass index $\left[\mathrm{kg} / \mathrm{m}^{2}\right]$ & $32.68 \pm 5.58$ & $32.73 \pm 5.40$ & $32.65 \pm 6.57$ & 0.912 \\
\hline Diabetes mellitus & $92(41.1 \%)$ & $71(48.9 \%)$ & $21(26.5 \%)$ & $<0.001$ \\
\hline Hypertension & $111(49.6 \%)$ & $87(60.0 \%)$ & $24(30.3 \%)$ & $<0.001$ \\
\hline Hypercholesterolemia & $94(42.0 \%)$ & $63(43.4 \%)$ & $31(39.2 \%)$ & 0.542 \\
\hline Current smoking & $134(59.8 \%)$ & $94(64.8 \%)$ & $40(50.6 \%)$ & 0.038 \\
\hline History of angina pectoris & $98(43.8 \%)$ & $56(38.6 \%)$ & $42(53.2 \%)$ & 0.13 \\
\hline Left ventricular ejection fraction [\%] & $51.0 \pm 10.8$ & $50.8 \pm 11.5$ & $51.4 \pm 9.6$ & 0.662 \\
\hline Peak troponin I [ng/mL] & $6.8 \pm 8.0$ & $6.8 \pm 8.7$ & $6.7 \pm 6.5$ & 0.909 \\
\hline Serum creatinine $[\mathrm{mg} / \mathrm{dL}]$ & $1.19 \pm 0.5$ & $1.17 \pm 0.46$ & $1.2 \pm 0.5$ & 0.64 \\
\hline Uric acid [mg/dL] & $5.4 \pm 5.1$ & $5.7 \pm 6.3$ & $5.1 \pm 1.7$ & 0.421 \\
\hline Gamma-glutamyl transferase [U/L] & $23.9 \pm 19.3$ & $24.9 \pm 21.3$ & $2.22 \pm 15.2$ & 0.319 \\
\hline \multicolumn{5}{|l|}{ Previous medications } \\
\hline Aspirin & $75(33.5 \%)$ & $45(32.0 \%)$ & $30(37.9 \%)$ & 0.453 \\
\hline Statin & $44(19.6 \%)$ & $27(18.6 \%)$ & $17(21.5 \%)$ & 0.602 \\
\hline Nitrates & $32(14.3 \%)$ & $5(10.3 \%)$ & $17(21.5 \%)$ & 0.82 \\
\hline ACEI/ARB & $62(27.7 \%)$ & $42(28.9 \%)$ & $20(25.3 \%)$ & 0.560 \\
\hline Beta-blockers & $91(40.6 \%)$ & $60(41.3 \%)$ & $31(39.2 \%)$ & 0.755 \\
\hline ССВ & $61(27.2 \%)$ & $41(28.2 \%)$ & $20(25.3 \%)$ & 0.634 \\
\hline \multicolumn{5}{|l|}{ Hematological parameters } \\
\hline Red blood cell count $\left[\times 10^{6} / \mu \mathrm{L}\right]$ & $5.20 \pm 0.52$ & $5.24 \pm 0.51$ & $5.13 \pm 0.55$ & 0.139 \\
\hline Platelet count $\left[\times 10^{3} / \mu \mathrm{L}\right]$ & $225.42 \pm 87.52$ & $250.11 \pm 85.44$ & $265.19 \pm 90.98$ & 0.219 \\
\hline WBC count $\left[\times 10^{3} / \mu \mathrm{L}\right]$ & $8.50 \pm 1.05$ & $9.01 \pm 0.95$ & $7.57 \pm 0.35$ & $<0.001$ \\
\hline \multicolumn{5}{|l|}{ WBC subtype: } \\
\hline Neutrophil $\left[\times 10^{3} / \mu \mathrm{L}\right]$ & $6.83 \pm 0.92$ & $7.29 \pm 0.81$ & $6.00 \pm 0.33$ & $<0.001$ \\
\hline Lymphocyte $\left[\times 10^{3} / \mu \mathrm{L}\right]$ & $1.40 \pm 0.24$ & $1.40 \pm 0.25$ & $1.42 \pm 0.22$ & 0.44 \\
\hline Monocyte $\left[\times 10^{3} / \mu \mathrm{L}\right]$ & $0.46 \pm 0.20$ & $0.46 \pm 0.21$ & $0.45 \pm 0.17$ & 0.808 \\
\hline NLR & $4.99 \pm 1.04$ & $5.37 \pm 1.03$ & $4.31 \pm 0.63$ & $<0.001$ \\
\hline $\mathrm{P} / \mathrm{L}$ ratio & $186.09 \pm 69.20$ & $184.18 \pm 70.42$ & $189.61 \pm 67.21$ & 0.576 \\
\hline \multicolumn{5}{|c|}{ Angiographic and procedural characteristics } \\
\hline Number of diseased vessels & $1.7 \pm 0.8$ & $1.7 \pm 0.2$ & $1.8 \pm 0.4$ & 0.46 \\
\hline \multicolumn{5}{|l|}{ Culprit vessel: } \\
\hline LM & $8(3.6 \%)$ & $7(4.8 \%)$ & $1(0.0 \%)$ & 0.559 \\
\hline LAD & $111(49.6 \%)$ & $71(48.9 \%)$ & $40(50.6 \%)$ & \\
\hline LCX & $71(31.7 \%)$ & $44(30.3 \%)$ & $27(34.1 \%)$ & \\
\hline RCA & $25(11.2 \%)$ & $18(12.4 \%)$ & $7(8.8 \%)$ & \\
\hline Culprit not clearly identified & $9(4 \%)$ & $5(3.4 \%)$ & $4(5.1 \%)$ & \\
\hline Stenosis of culprit vessel [\%] & $80.1 \pm 9.2$ & $78.1 \pm 8.3$ & $83.6 \pm 9.8$ & $<0.001$ \\
\hline \multicolumn{5}{|l|}{ Treatment decision: } \\
\hline $\mathrm{PCl}$ & $198(88.4 \%)$ & $130(89.6 \%)$ & $75(94.9 \%)$ & 0.519 \\
\hline CABG & $7(3.1 \%)$ & $6(4.1 \%)$ & $1(1.2 \%)$ & \\
\hline Conservative & $12(5.4 \%)$ & $9(6.2 \%)$ & $3(3.7 \%)$ & \\
\hline \multicolumn{5}{|l|}{ Rentrop grade: } \\
\hline 0 & & $92(41.1 \%)$ & & \\
\hline 1 & & $53(23.7 \%)$ & & \\
\hline 2 & & $47(21.0 \%)$ & & \\
\hline 3 & & $32(14.3 \%)$ & & \\
\hline
\end{tabular}

ACEI - angiotensin converting enzyme inhibitors; ARB - angiotensin receptor blocker; CCB — calcium-channel blockers; WBC — white blood cell; NLR - neutrophil to lymphocyte ratio, P/L — platelet to lymphocyte; LM — left main; LAD — left anterior descending; LCX — left circumflex; RCA - right coronary artery; $\mathrm{PCl}$ - percutaneous coronary intervention; CABG — coronary artery bypass graft 
Table 2. Multivariate logistic regression analysis to find the independent predictors of poor collateral development in study patients.

\begin{tabular}{lcccccc}
\hline & B & SE & Sig. & Exp (B) & 95\% confidence interval Exp (B) \\
\cline { 6 - 7 } & & & & & Lower & Upper \\
\hline Neutrophil $\left(\geq 6.25 \times 10^{3} / \mu \mathrm{L}\right)$ & 3.099 & 0.732 & 0.000 & 22.169 & 5.279 & 93.110 \\
NLR $(\geq 4.5)$ & 1.400 & 0.599 & 0.019 & 4.056 & 1.254 & 13.113 \\
WBC $\left(\geq 7.85 \times 10^{3} / \mu \mathrm{L}\right)$ & 2.487 & 0.691 & 0.000 & 12.030 & 3.106 & 46.591 \\
Age $(\geq 70$ years) & -1.652 & 0.621 & 0.008 & 0.192 & 0.057 & 0.647 \\
Diabetes mellitus & 2.757 & 0.766 & 0.000 & 15.748 & 3.512 & 70.613 \\
Male & 0.566 & 0.568 & 0.319 & 1.761 & 0.579 & 5.361 \\
Hypertension & 0.658 & 0.546 & 0.228 & 1.931 & 0.662 & 5.629 \\
Smoking & 1.008 & 0.566 & 0.075 & 2.741 & 0.903 & 8.319 \\
\hline
\end{tabular}

B - regression coefficient; NLR - neutrophil to lymphocyte ratio; WBC - white blood cell

Table 3. Simplified MILERI score calculation as transformed from the regression coefficients.

\begin{tabular}{lcc}
\hline Score element & B & Score point \\
\hline Neutrophil $\left(\geq 6.25 \times 10^{3} / \mu \mathrm{L}\right)$ & 3.099 & 2 \\
NLR $(\geq 4.5)$ & 1.400 & 1 \\
WBC $\left(\geq 7.85 \times 10^{3} / \mu \mathrm{L}\right)$ & 2.487 & 2 \\
Age $(\geq 70$ years $)$ & -1.652 & -1 \\
Diabetes mellitus & 2.757 & 2 \\
\hline
\end{tabular}

$B$ - regression coefficient for the parameter; NLR - neutrophil to lymphocyte ratio; WBC - white blood cell

Table 4. Comparison of MILERI scores in study patients with poor and good coronary collateral circulation (CCC).

\begin{tabular}{lcccc}
\hline $\begin{array}{l}\text { MILERI } \\
\text { score }\end{array}$ & $\begin{array}{c}\text { Poor } \\
\text { CCC }\end{array}$ & $\begin{array}{c}\text { Good } \\
\text { CCC }\end{array}$ & Total & P \\
\hline$\leq 1$ & 1 & 29 & 30 & $<0.001$ \\
$2-3$ & 14 & 41 & 55 & \\
$\geq 4$ & 130 & 9 & 139 & \\
Total & 145 & 79 & 224 & \\
\hline
\end{tabular}

flow may increase significantly over time [4]. In a previous study population, angiographic collaterals to myocardial tissue distal to an acutely occluded coronary vessel were detected in $69 \%$ patients during the acute phase [5]. This prevalence increased to $75 \%$ between $3 \mathrm{~h}$ and $6 \mathrm{~h}$ following symptom onset. Some other reports also showed early evidence of angiographic collateral vessels in acute ST-elevation myocardial infarction and NSTEMI [6]. The protective effects of angiographically visible collateral vessels in acute setting of infarction include a reduction in ischemic damage and prevention of fatal arrhythmias and aneurysm formation [7]. Residual blood flow carried by collaterals at the time of acute occlusion is also associated with positively influenced post infarct re-modeling and preserved myocardial function [8]. Therefore, we have a considerable interest in developing a model to assess the degree of coronary collateralization in the setting of an acute NSTEMI. Prior to our study, no scoring model for predicting poor collateral vessels in patients with acute infarction has been established.

Our study showed that presence of diabetes mellitus, elevated WBC and neutrophil counts and NLR on admission were independent predictors of poor CCC in patients with acute NSTEMI, whereas older age emerged as a negative indicator. Based on the results of the logistic regression analysis, we developed a simplified clinical score to predict poor collateral development by transforming the regression coefficient of each variable into an equivalent accurately weighted risk integer score. Therefore, poor collateralization can be easily and accurately assessed from simple clinical and laboratory variables on initial presentation of the patient in emergency room. The risk factors are all routinely measured and do not require expensive, time consuming or complicated technology to investigate. The clinician would simply collect routine data, total the scores for each variable, then predict the degree of collateralization. The final model was based on 5 variables which were significant at the $p<0.05$ level following multivariable logistic regression analysis. The total score for each patient was calculated by assigning 2 points 
for elevated WBC $\left(\geq 7.85 \times 10^{3} / \mu \mathrm{L}\right)$ and neutrophil $\left(\geq 6.25 \times 10^{3} / \mu \mathrm{L}\right)$ counts, 1 point for $\mathrm{NLR}(\geq 4.5)$ and -1 point for older age ( $\geq 70$ years old). The cut of values for each parameter were identified in the ROC curve analysis. The model was informative in $75 \%$ of patients with scores either $\leq 1$ or $\geq 4$. Sensitivity and specificity of the model in predicting poor collateralization in these patients were $99.2 \%$ and $76.3 \%$, respectively. The model has excellent predictive ability in selected patients.

Collateral development is a complex multistep process. It involves multiple inflammatory cell types as well as components of the extracellular matrix. Previous studies have shown that poor collateralization in $\mathrm{CAD}$ was related to a low grade inflammation, as evidenced by increased high sensitive $C$ reactive protein levels $[9,10]$. Acute-phase reactants and inflammatory cytokines such as tumor necrosis factor- $\alpha$ and interleukin- 6 have been found to be the predictors of insufficient coronary collaterals [11]. Some investigators also reported an association between poorly developed collateral vessels and an elevated concentration of soluble adhesion molecules [12]. These data have clearly demonstrated that increased inflammatory activity was associated with poor collateralization. WBC and its subtypes play a major role in modulating the inflammatory response. Effect of total leukocyte count on adverse coronary events is well demonstrated in the literature, however the data on the relationship between leukocyte subtypes and coronary collateral development is insufficient. At the cellular level, inflammatory cells play an important role in collateralization. In a series of experimental studies with animals, monocytes were shown to be essential elements for collateral development [13]. Higher circulating monocyte counts related to good collateral development in patients with stable angina [14]. A recent study relieved that increased CD14++CD16monocyte count predicts good collateralization in patients with stable angina [15]. On the other hand, two previous papers found increased leukocyte counts to be associated with poorly developed CCC in chronic total occlusion [16, 17]. In contrast to these findings, some investigators think that proinflammatory enzymes and cytokines released from these cells rather than leukocytes may play a role on collateral development in chronic total occlusion [18]. Currently, there are insufficient data regarding the relation between white blood cell subtypes and collateral development in acute infarction. Because ischemia during acute coronary occlusion appears to be a trigger for recruitment of leukocytes, we sought to investigate whether leukocyte subtypes in peripheral blood are related to the degree of collateral function in patients with acute infarction. We studied patients with acute NSTEMI and found that red blood cell and platelet counts did not differ between two groups with poor and good CCC. Lymphocyte and monocyte counts and platelet to lymphocyte ratios were also similar. However, patients with poor CCC have significantly higher WBC and neutrophil counts compared to those with good CCC.

Leukocytosis is a common finding in acute myocardial infarction that reflects the infiltration of WBCs into damaged tissue in response to ischemia and reperfusion. Particularly NLR is a combined factor of both inflammation and immune reaction. As a simple and noninvasive marker, NLR, in part of blood count, is a recent emerged better reflector of inflammation and endothelial dysfunction which have been evaluated widely in several cardiovascular diseases. Recently, a few studies revealed that elevated NLR was associated with impaired collateralization, however patients in these reports had stable CAD with chronic coronary total occlusions $[17,19-22]$. No data are available investigating the association of NLR with collateral function in acute setting of myocardial infarction. In our study, patients with poor CCC had significantly higher NLR compared to those with good collateralization. We found that NLR is an independent predictor of poor collateral development in acute NSTEMI. The association between NLR and poor collateralization may be explained by increased inflammatory activity and endothelial dysfunction, since a higher NLR indicates a higher level of inflammation. Whether it is the cause or the effect, NLR is associated with poor collateralization in the setting of acute myocardial infarction.

Our finding was consistent with previous data indicating that collateral growth is impaired in type-2 diabetes and metabolic syndrome [23, 24]. One of the major characteristics of diabetes is the persistent baseline inflammatory state characterized by elevated oxidative stress and endothelial dysfunction consistently observed in the vasculature and the myocardium. Endothelial cell function is essential for collateral formation. Nitric oxide is critically required for collateral development. Accordingly, diabetes mellitus and metabolic syndrome severely impair coronary collateral growth. In contrast to other studies, our data confirmed a negative association between older age and poor collateralization. Age emerged as a negative predictor of impaired collateralization in 
our scoring model. There has been some evidence from experimental studies that aging negatively affects collateral remodeling via impaired endothelial nitric oxide synthase pathways and by increased oxidative stress in coronary arterioles [25]. However, in the setting of an acute infarction, the human collateral function can be a direct indicator of CAD severity. Elderly patients probably have more severe disease which itself positively influences collateral development.

\section{Conclusions}

This study presents the first prediction model for degree of coronary collateralization in patients with acute NSTEMI. Our score uses simple clinical and laboratory parameters that are readily available for bedside use and provides a valuable tool for clinical decision-making.

\section{Conflict of interest: None declared}

\section{References}

1. Rentrop KP, Cohen M, Blanke H, Phillips RA. Changes in collateral channel filling immediately after controlled coronary artery occlusion by an angioplasty balloon in human subjects. J Am Coll Cardiol, 1985; 5: 587-592. doi: 10.1016/S0735-1097(85)80380-6.

2. Sullivan LM, Massaro JM, D'Agostino RB Sr. Presentation of multivariate data for clinical use: The Framingham Study risk score functions. Stat Med, 2004; 23: 1631-1660. doi: 10.1002/ sim. 1742 .

3. Meier P, Hemingway H, Lansky AJ, Knapp G, Pitt B, Seiler C. The impact of the coronary collateral circulation on mortality: A meta-analysis. Eur Heart J, 2012; 33: 614-621. doi: 10.1093/ eurheartj/ehr308.

4. Elsman P, van't Hof AW, de Boer MJ et al.; Zwolle Myocardial Infarction Study Group. Role of collateral circulation in the acute phase of ST-segment-elevation myocardial infarction treated with primary coronary intervention. Eur Heart J, 2004; 25: 854-858. doi: 10.1016/j.ehj.2004.03.005.

5. Waldecker B, Waas W, Haberbosch W, Voss R, Wiecha J, Tillmanns H. [Prevalence and significance of coronary collateral circulation in patients with acute myocardial infarct]. Z Kardiol, 2002; 91: 243-248. doi: 10.1007/s003920200018.

6. Bahrmann P, Rach J, Desch S, Schuler GC, Thiele H. Incidence and distribution of occluded culprit arteries and impact of coronary collaterals on outcome in patients with non-ST elevation myocardial infarction and early invasive treatment strategy. Clin Res Cardiol, 2011; 100: 457-467. doi: 10.1007/s00392-010-0269-9.

7. Seiler C, Stoller M, Pitt B, Meier P. The human coronary collateral circulation: Development and clinical importance. Eur Heart J, 2013; 34: 2674-2682. doi: 10.1093/eurhearti/eht195.

8. Seiler C. The human coronary collateral circulation. Eur J Clin Invest, 2010; 40: 465-476. doi: 10.1111/j.1365-2362.2010.02282.x.

9. Kerner A, Gruberg L, Goldberg A et al. Relation of C-reactive protein to coronary collaterals in patients with stable angina pectoris and coronary artery disease. Am J Cardiol, 2007; 99: 509-512. doi: 10.1177/0003319707309118.
10. Kadı H, Ceyhan K, Karayakalı M, Koç F, Celik A, Onalan O. [The relationship between coronary collateral circulation and blood high-sensitivity C-reactive protein levels]. Turk Kardiyol Dern Ars, 2011; 39: 23-28.

11. Seiler C, Pohl T, Billinger M, Meier B. Tumor necrosis factor alpha concentration and collateral flow in patients with coronary artery disease and normal systolic left ventricular function. Heart, 2003; 89: 96-97.

12. Guray U, Erbay AR, Guray Y et al. Poor coronary collateral circulation is associated with higher concentrations of soluble adhesion molecules in patients with single-vessel disease. Coron Artery Dis, 2004; 15: 413-417.

13. Heil M, Ziegelhoeffer T, Wagner S et al. Collateral artery growth (arteriogenesis) after experimental arterial occlusion is impaired in mice lacking CC-chemokine receptor-2. Circ Res, 2004; 94: 671-677. doi: 10.1161/01.RES.0000122041.73808.B5.

14. Kocaman SA, Arslan U, Tavil Y, Okuyan H, Abaci A, Cengel A. Increased circulating monocyte count is related to good collateral development in coronary artery disease. Atherosclerosis, 2008; 197: 753-756. doi: 10.1016/j.atherosclerosis.2007.07.010.

15. Arslan U, Kocaoğlu İ, Falay MY, Balcı M, Duyuler S, Korkmaz A. The association between different monocyte subsets and coronary collateral development. Coron Artery Dis, 2012; 23: 16-21. doi: 10.1097/MCA.0b013e32834df5b3.

16. van der Hoeven NW, Teunissen PF, Werner GS et al. Clinical parameters associated with collateral development in patients with chronic total coronary occlusion. Heart, 2013; 99: 1100-1105. doi: 10.1136/heartjnl-2013-304006.

17. Kalkan M, Sahin M, Kalkan A et al. The relationship between the neutrophil-lymphocyte ratio and the coronary collateral circulation in patients with chronic total occlusion. Perfusion, 2014; 29: 360-366. doi: 10.1177/0267659114538483.

18. Oğuz D, Atmaca Y, Ozdöl C, Ozdemir AO, Kaya CT, Erol C. The relationship between coronary collateral artery development and inflammatory markers. Anadolu Kardiyol Derg, 2014; 14: 336-341. doi: 10.5152/akd.2014.4612.

19. Uysal OK, Turkoglu C, Sahin DY et al. The relationship between neutrophil-to-lymphocyte ratio and coronary collateral circulation. Clin Appl Thromb Hemost, 2015; 21: 329-333. doi: 10.1177/1076029613503399.

20. Nacar AB, Erayman A, Kurt M et al. The relationship between coronary collateral circulation and neutrophil/lymphocyte ratio in patients with coronary chronic total occlusion. Med Princ Pract, 2015; 24: 65-69. doi: 10.1159/000365734.

21. Ayhan S, Ozturk S, Erdem A et al. Hematological parameters and coronary collateral circulation in patients with stable coronary artery disease. Exp Clin Cardiol, 2013; 18: e12-5.

22. Akın F, Ayça B, Çelik Ö, Şahin C. Predictors of poor coronary collateral development in patients with stable coronary artery disease: Neutrophil-to-lymphocyte ratio and platelets. Anatol J Cardiol, 2015; 15: 218-223. doi: 10.5152/akd.2014.5263.

23. Sun $Z$, Shen Y, Lu L et al. Clinical and angiographic features associated with coronary collateralization in stable angina patients with chronic total occlusion. J Zhejiang Univ Sci B, 2013; 14: 705-712. doi: 10.1631/jzus.BQICC704.

24. Rocic P. Why is coronary collateral growth impaired in type II diabetes and the metabolic syndrome? Vascul Pharmacol, 2012; 57: 179-186. doi: 10.1016/j.vph.2012.02.001.

25. Epstein SE, Lassance-Soares RM, Faber JE, Burnett MS. Effects of aging on the collateral circulation, and therapeutic implications. Circulation, 2012; 125: 3211-3219. doi: 10.1161/CIRCULATIONAHA.111.079038. 